\title{
An Exploratory Randomized Phase II Trial Comparing CDDP Plus S-1 With Bevacizumab and CDDP Plus Pemetrexed With Bevacizumab Against Patients With Advanced Non-squamous Non-small Cell Lung Cancer
}

\author{
KYOICHI KAIRA ${ }^{1,2}$, HISAO IMAI ${ }^{3}$, RYOUSUKE SOUMA ${ }^{4}$, REIKO SAKURAI ${ }^{1}$, YOSUKE MIURA ${ }^{1,3}$, \\ NORIAKI SUNAGA ${ }^{1}$, NORIMITSU KASAHARA ${ }^{1}$, YUSUKE TSUKAGOSHI ${ }^{1}$, YASUHIKO KOGA ${ }^{1}$, \\ SHINSUKE KITAHARA ${ }^{1}$, MIE KOTAKE ${ }^{3,5}$, KOICHI MINATO $^{3}$, ICHIRO NARUSE ${ }^{6}$, \\ YASUTSUGU FUKUSHIMA ${ }^{4}$, TAKESHI HISADA ${ }^{1}$ and TAMOTSU ISHIZUKA ${ }^{7}$ \\ ${ }^{1}$ Department of Respiratory Medicine, Gunma University Graduate School of Medicine, Gunma, Japan; \\ ${ }^{2}$ Department of Respiratory Medicine, Comprehensive Cancer Center, \\ International Medical Center, Saitama Medical University, Saitama, Japan; \\ ${ }^{3}$ Division of Thoracic Oncology, Gunma Prefectural Cancer Center, Gunma, Japan; \\ ${ }^{4}$ Department of Respiratory Medicine and Clinical Immunology, Dokkyo Saitama Medical Center, Saitama, Japan; \\ ${ }^{5}$ Department of Respiratory Medicine, Shibukawa Medical Center, Gunma, Japan; \\ ${ }^{6}$ Department of Respiratory Medicine, Hidaka Hospital, Gunma, Japan; \\ ${ }^{7}$ Third Department of Internal Medicine, Faculty of Medical Sciences, University of Fukui, Fukui, Japan
}

\begin{abstract}
Background/Aim: It remains unclear which chemotherapeutic regimens are better for the addition of bevacizumab. We conducted an exploratory randomized phase II trial comparing first-line $S-1$ plus cisplatin with bevacizumab and pemetrexed plus cisplatin with bevacizumab in patients with advanced non-squamous non-small cell lung cancer (NSCLC). Patients and Methods: Chemotherapy-naïve patients received $S-1\left(80 \mathrm{mg} / \mathrm{m}^{2}\right)$ from day 1 to day 14 plus cisplatin $\left(80 \mathrm{mg} / \mathrm{m}^{2}\right)$ on day 1 with bevacizumab $(15 \mathrm{mg} / \mathrm{kg})$ on day 1 , followed by maintenance with bevacizumab plus $S-1$ (SCB) on day 1 every 3 weeks and pemetrexed (500 $\left.\mathrm{mg} / \mathrm{m}^{2}\right)$ on day 1 plus cisplatin $\left(75 \mathrm{mg} / \mathrm{m}^{2}\right)$ on day 1 with bevacizumab $(15 \mathrm{mg} / \mathrm{kg})$ on day 1 followed by maintenance bevacizumab plus pemetrexed (PCB) on day 1 every 3 weeks. The expression of thymidylate synthase (TS) was analyzed using immunohistochemistry. Results: Forty-eight patients were enrolled in this study, and eligible patients were randomly assigned at 1:1 ratio to receive $S C B(n=24)$ or $P C B$ $(n=24)$. The median number of chemotherapy and
\end{abstract}

Correspondence to: Kyoichi Kaira, Department of Respiratory Medicine, Gunma University Graduate School of Medicine, Showamachi, Maebashi, Gunma 371-8511, Japan. Tel: +81 272208222, Fax: +81 272020212, e-mail: kkaira1970@yahoo.co.jp

Key Words: CDDP, S-1, pemetrexed, phase 2, thymidylate synthase, bevacizumab. maintenance therapy for SCB and PCB was 4 (range, 1-6 cycles) and 4 (range, 2-6 cycles), and 5 (range, 0-39 cycles) and 5 (range, 0-28 cycles), respectively. The overall response rate (ORR) for PCB and SCB were $54.2 \%$ and $83.3 \%$, respectively $(p=0.06)$. The median progression-free survival $(P F S)$ and overall survival $(O S)$ for PCB and SCB were 406 and 351 days, $(p=0.96)$, and 678 and 1190 days, respectively $(p=0.23)$. The mild adverse events were observed in both regimens. TS expression was more predictive of the chemotherapeutic response in $S C B$ compared to PCB, but not for PFS. Conclusion: The combination regimen of $S C B$ was identified as having a similar activity and tolerability to that of PCB in patients with advanced non-squamous NSCLC.

Non-small cell lung cancer (NSCLC) is the leading cause of cancer-related deaths worldwide. If detected early, surgical resection is recommended. However, systemic chemotherapy is generally required for patients who are diagnosed with advanced NSCLC. Molecular targeting therapy is a candidate for patients with driver mutations, such as epidermal growth factor receptor $(E G F R)$, however, these treatments have yet to replace the combination of platinum-based chemotherapy for prolonged survival (1). The addition of bevacizumab in the regimen of cytotoxic chemotherapy is known to improve the overall response rate (ORR) and progression-free survival (PFS) for patients with advanced non-squamous NSCLC (2-4). The combination of several chemotherapeutic regimens with bevacizumab provide a useful and effective 
treatment; however, it remains unclear which combinations contribute best to survival.

Recently, we reported a phase II study to assess the efficacy and safety of S-1 plus cisplatin with bevacizumab followed by maintenance bevacizumab in patients with advanced non-squamous NSCLC (5). This yielded an ORR and a disease control rate (DCR) of $71 \%$ and $100 \%$, respectively, and median PFS and overall survival (OS) of 7.0 months and 20.0 months, respectively, with acceptable toxicities (5). Urata et al., have also conducted a phase II study of S-1 and carboplatin plus bevacizumab in patients with non-squamous NSCLC and have achieved an ORR of $54.2 \%$ and median PFS of 6.8 months with tolerable toxicities (6). Considering these results, we feel that combination of S-1 and platinum plus bevacizumab is effective and tolerable for chemo-naïve patients with nonsquamous NSCLC. S-1 (Tahiho Pharmaceutical Co., Ltd, Tokyo, Japan) is an oral anticancer agent designed to enhance the antitumor effect and to suppress gastrointestinal toxicities. Platinum-based combination chemotherapy, including S-1 is recommended as a standard regimen for patients with advanced $\operatorname{NSCLC~}(7,8)$, as the targeting molecule of S-1, thymidylate synthase (TS), is known to be important for the suppression of tumor progression (9). Protein expression levels of TS can also predict the outcome after administration of platinum-based chemotherapy, including S-1 (10). However, TS activity is diminished by pemetrexed, revealing the potential of TS activity as a molecular target of pemetrexed (11). Clinically, the combination of pemetrexed and cisplatin with bevacizumab contributes to prolonged survival of patients with advanced NSCLC and is a standard first-line chemotherapeutic regimen (4). However, little is known on how S-1 and pemetrexed compare with each other, regardless of targeting the same molecule.

We conducted an exploratory randomized phase II study to compare the efficacy of cisplatin plus S-1 with bevacizumab (SCB) and cisplatin plus pemetrexed with bevacizumab (PCB) in patients with advanced non-squamous NSCLC. We also performed an exploratory investigation of whether thymidylate synthase (TS), excision repair crosscomplementation group 1 (ERCC1), Ki-67, or vascular endothelial growth receptor (VEGR) could predict the efficacy and outcome of S-1 or pemetrexed-based regimens, using tumor tissue from primary sites.

\section{Patients and Methods}

Patient eligibility. Eligible patients had: i) cytologically and/or histologically proven unresectable stage IIIb, stage IV or recurrent non-squamous NSCLC, ii) no previous chemotherapy or radiotherapy, iii) an eastern clinical oncology group (ECOG) performance status (PS) of 0-1, iv) an age range of 20-74 years old, v) life expectancy of 12 weeks or more, vi) measurable lesions, as
Table I. Patient's demographics.

\begin{tabular}{|c|c|c|c|c|}
\hline Variables & $\begin{array}{c}\text { All } \\
\text { patients } \\
\mathrm{n}=48\end{array}$ & $\begin{array}{c}\text { CDDP/PEM/ } \\
\text { Bev } \\
n=24\end{array}$ & $\begin{array}{c}\text { CDDP/S-1/ } \\
\text { Bev } \\
n=24\end{array}$ & $p$-Value \\
\hline $\begin{array}{l}\text { Median age } \\
\text { years } \\
\text { (range) }\end{array}$ & $\begin{array}{c}65 \\
\text { (48-74 years) }\end{array}$ & $\begin{array}{c}66 \\
\text { (48-73 years) }\end{array}$ & $\begin{array}{c}64 \\
\text { (49-74 years) }\end{array}$ & - \\
\hline \multicolumn{5}{|c|}{ 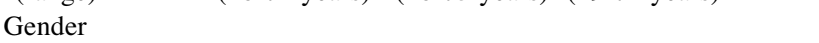 } \\
\hline $\begin{array}{l}\text { Male } \\
\text { Female }\end{array}$ & $\begin{array}{l}33 \\
15\end{array}$ & $\begin{array}{l}14 \\
10\end{array}$ & $\begin{array}{c}19 \\
5\end{array}$ & 0.11 \\
\hline \multicolumn{5}{|l|}{ Smoking } \\
\hline $\begin{array}{l}\text { Yes } \\
\text { No }\end{array}$ & $\begin{array}{l}31 \\
17\end{array}$ & $\begin{array}{l}11 \\
13\end{array}$ & $\begin{array}{l}20 \\
14\end{array}$ & 0.42 \\
\hline \multicolumn{5}{|l|}{ ECOG PS } \\
\hline $\begin{array}{l}0 \\
1\end{array}$ & $\begin{array}{l}37 \\
11\end{array}$ & $\begin{array}{c}16 \\
8\end{array}$ & $\begin{array}{c}21 \\
3\end{array}$ & 0.16 \\
\hline \multicolumn{5}{|l|}{ BSA } \\
\hline $\begin{array}{l}\leq 1.5 \\
>1.5\end{array}$ & $\begin{array}{l}17 \\
31\end{array}$ & $\begin{array}{c}9 \\
15\end{array}$ & $\begin{array}{c}8 \\
16\end{array}$ & $>0.99$ \\
\hline \multicolumn{5}{|l|}{ EGFR mutation } \\
\hline $\begin{array}{l}\text { Wild type } \\
\text { Mutant } \\
\text { Unknown }\end{array}$ & $\begin{array}{c}31 \\
6 \\
1\end{array}$ & $\begin{array}{c}21 \\
2 \\
1\end{array}$ & $\begin{array}{c}10 \\
4 \\
0\end{array}$ & 0.17 \\
\hline \multicolumn{5}{|l|}{ Histological type } \\
\hline $\begin{array}{l}\text { Adenocarcinoma } \\
\text { LCC }\end{array}$ & $\begin{array}{c}47 \\
1\end{array}$ & $\begin{array}{c}23 \\
1\end{array}$ & $\begin{array}{c}24 \\
0\end{array}$ & $>0.99$ \\
\hline \multicolumn{5}{|l|}{ Clinical stage } \\
\hline III & 3 & 1 & 2 & \\
\hline IV & 42 & 21 & 21 & $>0.99$ \\
\hline $\begin{array}{l}\text { Recurrence } \\
\text { after operation }\end{array}$ & 3 & 2 & 1 & \\
\hline $\begin{array}{l}\text { Cycle number of } \\
\text { induction CTx }\end{array}$ & & & & \\
\hline $\begin{array}{l}\text { Median } \\
\text { (range) }\end{array}$ & $\begin{array}{c}4 \\
\text { (1-6 cycles) }\end{array}$ & $\begin{array}{c}4 \\
\text { (2-6 cycles) }\end{array}$ & $\begin{array}{c}4 \\
(1-6 \text { cycles })\end{array}$ & 0.20 \\
\hline $\begin{array}{l}\text { Cycle number } \\
\text { of maintenance }\end{array}$ & & & & \\
\hline $\begin{array}{l}\text { Median } \\
\text { (range) }\end{array}$ & $\begin{array}{c}3 \\
(0-39 \text { cycles })\end{array}$ & $\begin{array}{c}5 \\
\text { (0-28 cycles) }\end{array}$ & $\begin{array}{c}5 \\
(0-39 \text { cycles })\end{array}$ & 0.79 \\
\hline
\end{tabular}

ECOG: Eastern cooperative oncology group; PS: performance status; EGFR: epidermal growth factor receptor; BSA: body surface area; LCC: large cell carcinoma; CDDP: cisplatin; PEM: pemetrexed; Bev: bevacuzumab; CTx: chemotherapy.

defined by the Response Evaluation Criteria in Solid Tumors (RECIST 1.1) (12), vii) and adequate hematological, hepatic, and renal dysfunction (serum creatinine $\leq 1.5 \mathrm{mg} \mathrm{dl}-1$ and creatinine clearance $\geq 60 \mathrm{ml} \mathrm{min}-1$ ). The exclusion criteria were: i) histological evidence of predominantly squamous cell carcinoma, ii) a primary tumor in close proximity to a major vessel or with cavitation, iii) a histology of gross hemoptysis ( $\geq 2.5 \mathrm{ml}$ ), iv) central nervous system or brain metastasis, v) a history of a thrombotic or hemorrhagic disorder, vi) medically uncontrolled hypertension, vii) clinically significant cardiovascular disease, viii) full-dose anticoagulation, ix) regular use of aspirin ( $\geq 325 \mathrm{mg} /$ day), $x$ ) pregnancy or lactation, and xi) a major surgical procedure in the 28 days prior to treatment. Patients with concomitant malignancy, active infectious diseases, or other serious medical problems were also ineligible. 
Table II. Response rate according to each regimen.

\begin{tabular}{lcccc}
\hline Regimen & & \multicolumn{2}{c}{ Response } \\
\cline { 2 - 5 } & No. of patients & CR & PR & SD \\
\hline $\begin{array}{l}\text { Cisplatin/Pemetrexed/Bevacizumab } \\
\text { Overall response rate }\end{array}$ & 24 & 0 & 13 & 11 \\
$\begin{array}{l}\text { Disease control rate (\%) (95\%CI) } \\
\text { Cisplatin/S-1/Bevacizumab }\end{array}$ & 24 & & $54.2 \%(95 \%$ CI, 32.8-74.4) \\
Overall response rate (\%) (95\%CI) \\
Disease control rate
\end{tabular}

CR: Complete response; PR: partial response; SD: stable disease; PD: progressive disease, 95\%CI: 95\% confidence interval.

The study was carried out in accordance with the Declaration of Helsinki and Japanese Good Clinical Practice guidelines. The protocol was approved by the ethics committees of the participating institutions, and all patients gave informed consent for study participation.

Study design and treatment. This was a prospective, randomized twoarm phase II study comparing i) first-line S-1 plus cisplatin with bevacizumab, followed by maintenance bevacizumab plus S-1 (SCB) and ii) pemetrexed plus cisplatin with bevacizumab, followed by maintenance bevacizumab plus pemetrexed (PCB) at 4 institutions in Japan. Eligible patients were randomly assigned in a ratio of $1: 1$ to receive either SCB or PCB. For SCB, S-1 was administered twice daily, following morning and evening meals. S-1 $\left(80 \mathrm{mg} / \mathrm{m}^{2}\right)$ was administered for 14 consecutive days, followed by a 7-day rest period. The dose of S-1 was selected as follows: i) $80 \mathrm{mg}$ per day for a patient with a body surface area (BSA) $<1.25 \mathrm{~m}^{2}$, ii) $100 \mathrm{mg}$ per day for a BSA $1.25-1.5 \mathrm{~m}^{2}$, and iii) $120 \mathrm{mg}$ per day for a BSA $>1.5 \mathrm{~m}^{2}$. Cisplatin $\left(60 \mathrm{mg} / \mathrm{m}^{2}\right)$ was administered on day 1 via continuous intravenous infusion for 60 minutes with $2500-3000 \mathrm{~mL}$ fluid hydration. For PCB, intravenous pemetrexed $\left(500 \mathrm{mg} / \mathrm{m}^{2}\right)$ was administered on day 1 and cisplatin $\left(75 \mathrm{mg} / \mathrm{m}^{2}\right)$ was administered on day 1 via continuous intravenous infusion for 60 minutes with 2500$3,000 \mathrm{~mL}$ fluid hydration. Bevacizumab was administered intravenously on day 1 for 90 minutes. In case where the first cycle infusion of bevacizumab was well tolerated, the second cycle infusion was delivered for 60 minutes, and all subsequent infusions were delivered for 30 minutes each. The patients on the SCB regimen were treated with S-1 at $80 \mathrm{mg} / \mathrm{m}^{2}$ twice a day for 14 consecutive days while cisplatin $\left(60 \mathrm{mg} / \mathrm{m}^{2}\right)$ and bevacizumab $(15 \mathrm{mg} / \mathrm{kg})$ were administered intravenously on day 1, and every 3 weeks for 4-6 cycles. The patients in the PCB treatment received pemetrexed $\left(500 \mathrm{mg} / \mathrm{m}^{2}\right)$ and cisplatin $\left(75 \mathrm{mg} / \mathrm{m}^{2}\right)$ plus bevacizumab $(15 \mathrm{mg} / \mathrm{kg})$ on day 1, and every 3 weeks for 4-6 cycles. Following these cycles, patients with a complete response (CR), partial response (PR), or stable disease $(\mathrm{SD})$ were treated with a maintenance therapy regimen of bevacizumab $(15 \mathrm{mg} / \mathrm{kg})$ plus $\mathrm{S}-1\left(80 \mathrm{mg} / \mathrm{m}^{2}\right)$ for the SCB group and bevacizumab $(15 \mathrm{mg} / \mathrm{kg})$ plus pemetrexed $\left(500 \mathrm{mg} / \mathrm{m}^{2}\right)$ for the PCB group every 3 weeks, until disease progression or intolerable toxicity was evident.

Treatment assessment. The primary endpoint of this study was the assessment of PFS, and the secondary endpoints were the evaluation of OS, ORR, and safety. Weekly evaluations included complete blood cell counts, differential counts, routine chemistry measurements, physical examination, and toxicity assessment. Acute toxicities were graded according to the Common Terminology Criteria for Adverse Events version 4.0 (13). Tumor responses were evaluated according to the Response Evaluation Criteria in Solid Tumors version 1.1 (12). Tumor status was evaluated every 2 cycles by a follow-up computed tomography (CT) scan. Second-line chemotherapy or other treatments following this study were not prohibited by the protocol.

Immunohistochemistry. Immunohistochemical staining was performed according to the procedure described in the previous reports (14-16). The following antibodies were used: i) mouse monoclonal antibody against ERCC1 (ABI2356; Abcam, Tokyo, Japan; 1.200 dilution), ii) rabbit monoclonal antibody against TS (D5B3, Cell Signaling Technology, Dancers, MA, USA; 1.200 dilution), iii) rabbit monoclonal antibody against VEGF (sc-7269, Santa Cruz Biothechnology, Japan; 1.100 dilution), and iv) mouse monoclonal antibody against Ki-67 (Dako, Glostrup, Denmark; 1:40 dilution). The expression of TS and VEGF were considered positive if cytoplasm and/or membrane staining was present, whereas ERCC1 and Ki-67 were considered positive if nuclear staining was evident. The percentage staining of TS, ERCC1, and VEGF was scored as follows: i) $1=0-10 \%$, ii) $2=11-25 \%$, iii) $3=26-50 \%$, and iv) $4=51-100 \%$. For TS, positive expression was defined when identified cancer cells obtained a staining score of 2, 3, and 4. For ERCC1 and VEGF, high expression was defined when identified cancer cells received a staining score of 3 or 4 . For Ki-67, a high density cellular area of the immunostained section was assessed. Approximately 1000 nuclei were counted on each slide. The median value of the Ki-67 labeling index was evaluated, and the tissues with positive tumor cells greater than the median value were defined as highly expressing ones. The sections were evaluated using a light microscope (Olympus, CX41/31) in a blind fashion by at least two of the authors.

Statistical analysis. Statistical significance was indicated by $p<0.05$. Fisher's exact tests were used to examine the association between two categorical variables. The Kaplan-Meier method was used to estimate survival as a function of time, and survival differences were analyzed by log-rank tests. The ORR was defined as the best response recorded from the initiation of treatment until disease progression or recurrence. Survival was recorded from the first day of the protocol treatment to the date of death or last follow-up, and 
the survival curves were calculated according to the Kaplan-Meier method. Overall survival (OS) was determined as the time from the first day of chemotherapy to death from any cause. Progression-free survival (PFS) was defined as the time from the first day of chemotherapy to the first sign of disease progression or death. Based on previous evidence (2-8), we assumed that a PFS of 8.5 months would indicate a potentially useful study registration, whereas a PFS of 5.0 months would constitute the lower limit of interest, with $\alpha=0.10$ and $\beta=0.20$. The sample setting was determined by selective design. The target sample size was 48 patients ( 24 for each treatment arm), taking into consideration patients who would prove to be ineligible for the study. Statistical analyses were performed using GraphPad Prism 4 (Graph Pad Software, San Diego, CA, USA) and JMP 14.0 (SAS Institute Inc., Cary, NC, USA).

\section{Results}

Patients characteristics. From June 2012 to October 2017, a total of 48 patients were enrolled in this study, and all patients were allocated to one of the two arms. All patients were treated with the corresponding doses and drugs according to the study criteria. Patient demographics were well balanced between the two arms (Table I). The median numbers of cycles of induction chemotherapy for PCB and SCB were 4.0 and 4.0, respectively. The median follow-up period was 632 days in the PCB arm and 567 days in the SCB arm.

Treatment delivery. Approximately $79.2 \%$ patients completed at least 4 cycles of $\mathrm{PCB}$, compared to $91.6 \%$ of patients treated with $\mathrm{SCB}$. Also, $75.0 \%$ of $\mathrm{PCB}$ patients were shifted to sequential maintenance therapy with pemetrexed and bevacizumab, compared to $79.2 \%$ of patients that received sequential maintenance therapy with $\mathrm{S}-1$ and bevacizumab. Dose reduction in the induction phase for $\mathrm{PCB}$ and $\mathrm{SCB}$ occurred in 2 and 0 patients, respectively, and 0 patients and 2 patients were discontinued from the treatment, respectively.

Efficacy and survival analysis. The ORR and DCR are listed in Table II. No patients exhibited CR and PD; however, PR and SD from the PCB group were observed in 13 and 20 patients, respectively, and 11 and 4 patients from the SCB group, respectively. ORR from $\mathrm{PCB}$ and SCB were $54.2 \%$ and $83.3 \%$, respectively $(p=0.06)$ while DCR rates were $100 \%$ and $100 \%$, respectively $(p>0.99)$. The median PFS for PCB and SCB administration was 406 and 351 days, respectively ( $p=0.96$ ) (Figure 1A), while OS was 678 and 1190 days, respectively ( $p=0.23$ ) (Figure 1B). Of all patients, 34 experienced recurrence and 31 died following initial chemotherapy. The median time to treatment failure (TTF) for PCB and PCB were 258 and 207 days, respectively $(p=0.65)$ (Figure 1C).

Adverse events. All patients were evaluated for safety and the main adverse events experienced are presented in Table
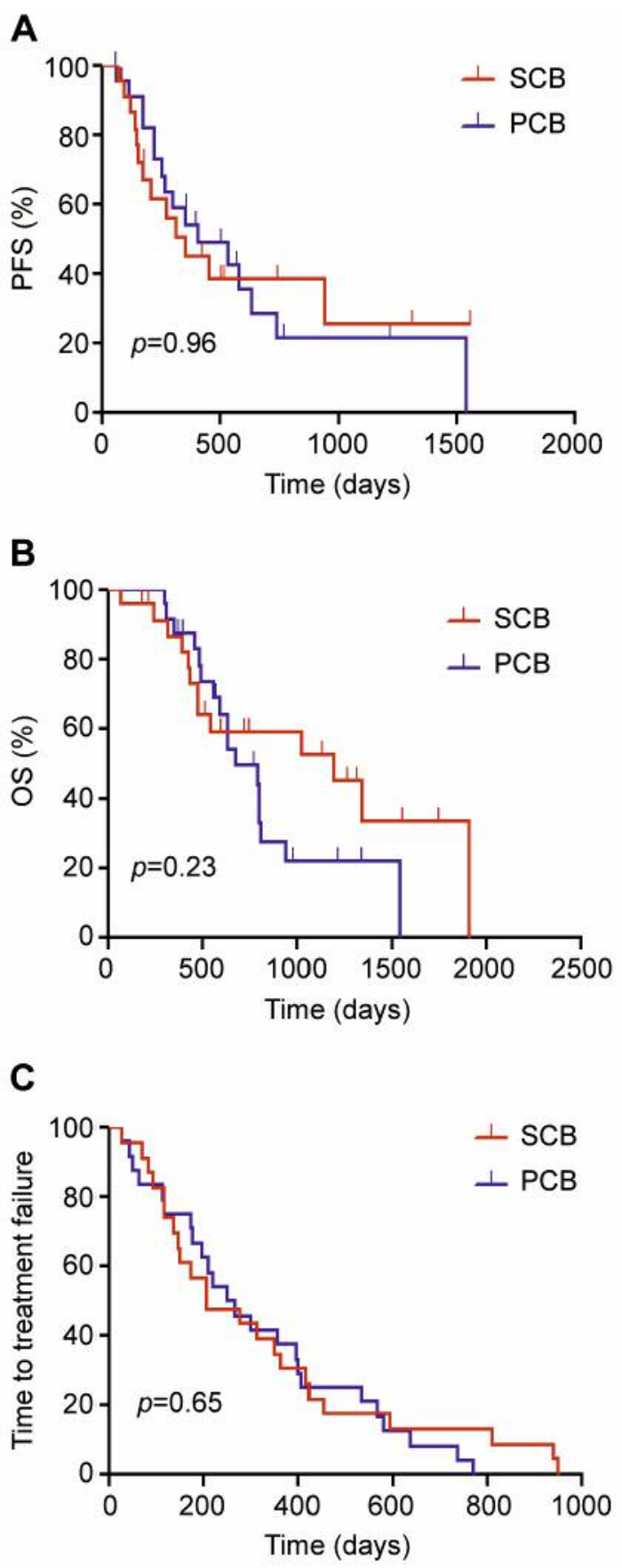

Figure 1. Kaplan-Meier survival curves comparing SCB and PCB. No statistically significant differences in PFS (A), OS (B) and TTF $(C)$ were observed between $S C B$ and $P C B$.

III. Adverse events that were commonly observed in the PCB and SCB arms, respectively, were as follows: i) neutropenia (all grades, $25.0 \%$ versus $45.8 \%$; $\geq$ grade $3,12.5 \%$ versus $12.5 \%$ ), ii) anemia (all grades, $28.5 \%$ versus $50.0 \%$; $\geq$ grade $3,0.0 \%$ versus $0.0 \%$ ), iii) anorexia (all grades, $29.2 \%$ versus 
Table III. Adverse events by each regimen.

\begin{tabular}{|c|c|c|c|c|}
\hline \multirow[t]{2}{*}{ Toxicity } & \multicolumn{2}{|c|}{ Cisplatin / Pemetrexed/Bevacizumab } & \multicolumn{2}{|c|}{ Cisplatin/S-1/Bevacizumab } \\
\hline & All grade & Grade $3 / 4(\%)$ & All grade & Grade $3 / 4(\%)$ \\
\hline Anemia & 8 & $0(0.0 \%)$ & 12 & $0(0.0 \%)$ \\
\hline Leukopenia & 7 & $0(0.0 \%)$ & 8 & $0(0.0 \%)$ \\
\hline Neutropenia & 6 & $3(12.5 \%)$ & 11 & $3(12.5 \%)$ \\
\hline Thrombocytopenia & 3 & $0(0.0 \%)$ & 6 & $0(0.0 \%)$ \\
\hline Nausea/Vomiting & 6 & $0(0.0 \%)$ & 11 & $0(0.0 \%)$ \\
\hline Anorexia & 7 & $1(4.1 \%)$ & 14 & $0(0.0 \%)$ \\
\hline Diarrhea & 2 & $0(0.0 \%)$ & 4 & $0(0.0 \%)$ \\
\hline Infection & 1 & $0(0.0 \%)$ & 1 & $1(4.1 \%)$ \\
\hline Constipation & 9 & $0(0.0 \%)$ & 9 & $0(0.0 \%)$ \\
\hline Skin rash & 1 & $1(4.1 \%)$ & 2 & $2(8.3 \%)$ \\
\hline AST/ALT & 2 & $0(0.0 \%)$ & 4 & $0(0.0 \%)$ \\
\hline Fatigue & 7 & $0(0.0 \%)$ & 6 & $0(0.0 \%)$ \\
\hline Fever & 0 & $0(0.0 \%)$ & 0 & $0(0.0 \%)$ \\
\hline Neuropathy & 6 & $0(0.0 \%)$ & 3 & $0(0.0 \%)$ \\
\hline Stomatitis & 5 & $0(0.0 \%)$ & 9 & $0(0.0 \%)$ \\
\hline Hypertension & 10 & $3(12.5 \%)$ & 2 & $1(4.1 \%)$ \\
\hline Paronychia & 0 & $0(0.0 \%)$ & 4 & $0(0.0 \%)$ \\
\hline Dysgeusia & 0 & $0(0.0 \%)$ & 7 & $0(0.0 \%)$ \\
\hline Pigmentation & 0 & $0(0.0 \%)$ & 8 & $0(0.0 \%)$ \\
\hline Urinary protein & 2 & $2(8.3 \%)$ & 3 & $1(4.1 \%)$ \\
\hline
\end{tabular}

$58.3 \%$; $\geq$ grade $3,4.1 \%$ versus $0.0 \%$ ), iv) constipation (all grades, $37.5 \%$ versus $37.5 \%$; $\geq$ grade $3,0.0 \%$ and $0.0 \%$ ), and v) hypertension (all grades, $41.6 \%$ versus $8.3 \%$; $\geq$ grade 3 , $12.5 \%$ and $4.1 \%$ ). All adverse effects were managed by supportive care and dose modification. No pulmonary toxicities, such as interstitial pneumonia or treatment-related deaths were observed during this study.

Exploratory analysis according to biomarkers. Immunohistochemical examination was performed using 36 primary lesions of NSCLC. Representative images of TS, ERCC1, $\mathrm{Ki}-67$, and VEGF are shown in Figure 2. All values in square brackets are presented for SCB, then $\mathrm{PCB}$, respectively. The rates of positive expression for TS and high expression for ERCC1 and VEGF were $47.3 \%(9 / 19)$ and $47.1 \%(8 / 17), 63.2 \%(12 / 19)$ and $58.8 \%(10 / 17)$, and $57.8 \%(11 / 19)$ and $47.1 \%(8 / 17)$, for SCB and PCB, respectively. The median Ki-67 labeling index was $20 \%$, ranging from 2 to $65 \%$ in all patients, and the high expression of $\mathrm{Ki}-67$ labeling index was observed in $44.4 \%$ [47.3\% (9/19) and 41.2\% (7/17)]. The survival analysis, according to these biomarkers, is shown in Figure 3 . The expression level of TS was identified as a significant prognostic marker for predicting the PFS and OS of SCB, but not PCB. Figure 1 shows the Kaplan-Meier survival curves according to the expression of TS. However, the expression level of these biomarkers did not predict the response following SCB and PCB (Figure 4).

\section{Discussion}

This prospective exploratory study compared SCB to PCB in patients with non-squamous NSCLC. Here, we found that the efficacy and tolerability of SCB is similar to those of PCB. Interestingly, the ORR of SCB was higher compared to that of PCB without statistical significance. As our previous study achieved an ORR of $71 \%$ on SCB, the $83.3 \%$ reported here was higher. Thus, the SCB in our present study may be biased due to the small sample size. The PFS primary endpoint was reasonable for the regimens of SCB and PCB here, compared to that of previous studies $(4,7,8)$. Our present study suggests $\mathrm{S}-1$ as an alternative to pemetrexed when platinum-based chemotherapy includes bevacizumab. S-1 is also cheaper than pemetrexed, proving it useful worldwide. Moreover, here our use of several biomarkers revealed the expression level of TS is significantly predictive of the PFS and OS of SCB, but not for that of PCB or ORR for either regimen. Further study is warranted to plan the phase III comparison of SCB with PCB. However, the standard first-line platinum-based chemotherapy treatment will need to be combined with immune check inhibitors (ICIs) in NSCLC patients without EGFR mutation. Thus, the combination of SCB with ICIs should be investigated in future trials.

Recently, we reported the efficacy and tolerability of SCB, and confirmed that its combination with bevacizumab was equivalent to what has been reported in previous studies (5, 


\section{A TS}

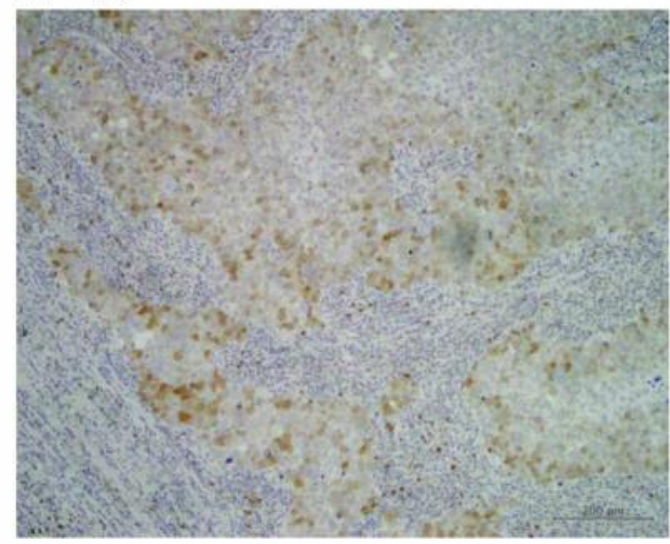

\section{C $\mathrm{Ki}-67$}

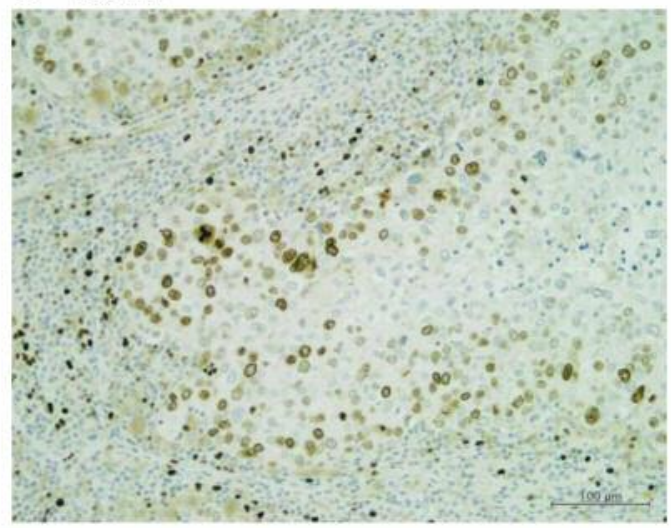

\section{B ERCC1}

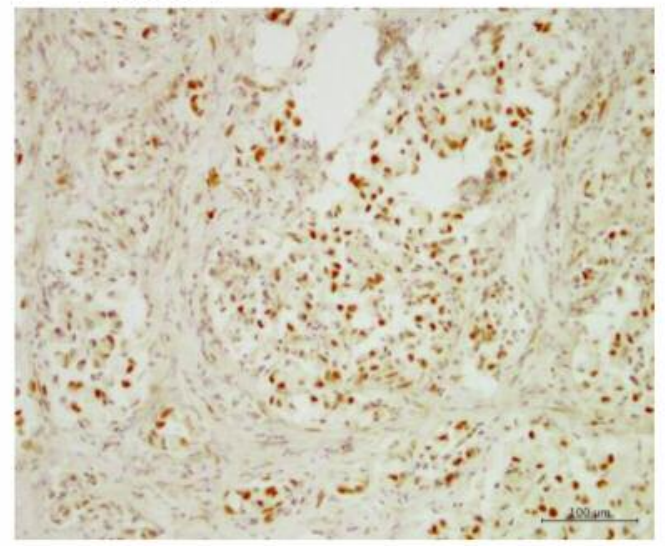

\section{VEGF}

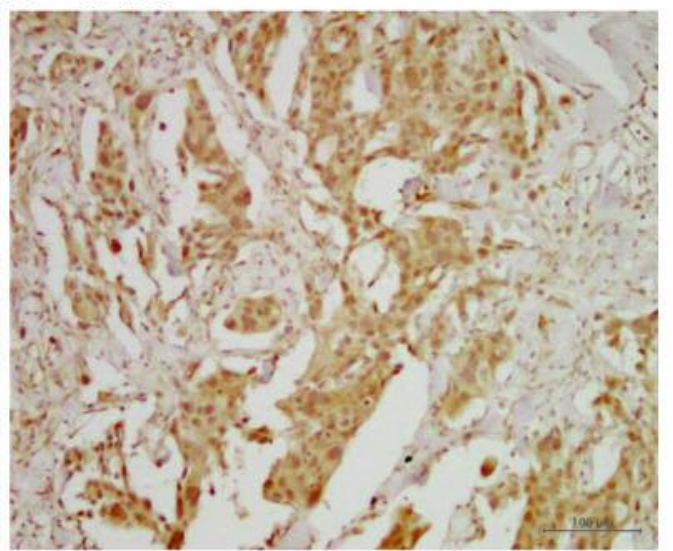

Figure 2. Representative images of TS (A), ERCC1 (B), Ki-67 (C) and VEGF (D). The expression of TS and VEGF were identified as cytoplasmic and/or membranous, whereas, ERCC1 and Ki-67 are nuclear. Scale bars: $100 \mu \mathrm{m}$.

6). However, it is not yet clear whether maintenance chemotherapy using S-1 with bevacizumab could be beneficial for the response and the survival of patients with non-squamous NSCLC $(17,18)$. Here, we used the regimen of SCB followed by maintenance therapy of S-1 plus bevacizumab, and feel that the number of cycles and tolerability of this maintenance therapy are comparable to that of pemetrexed plus bevacizumab. In the previous phase III study of PCB followed by pemetrexed plus bevacizumab, the ORR of induction chemotherapy was $55.5 \%$, and the PFS and OS of this PCB regimen were 10.2 months and 19.8 months, respectively, with acceptable toxicities (17). The results of this phase III study appear similar compared to those of PCB in our study, although the number of registered patients was different. The adverse events (AEs) in our study were less toxic compared to those of previous studies, and there was a difference in the frequency of AEs between SCB and PCB. Although the frequency of toxicities here may be biased due to the small sample size, we confirmed that the addition of S-1 with bevacizumab did not increase the frequency of AEs compared to that of pemetrexed and bevacizumab.

We also investigated the protein expression of TS, ERCC1, Ki-67, and VEGF within tumor tissues using immunohistochemistry, to explore predictive markers for PCB and SCB. Our data indicated that the negative expression of TS could accurately predict the favorable outcome of SCB but not of PCB, regardless of the limited sample size. A previous study also found that low expression of TS predicts a better response and longer survival, using S-1 and platinum-based chemotherapy (10). Further research is required to examine the relationship between chemotherapeutic treatments and predictive markers, such as TS and ICI-related markers. 

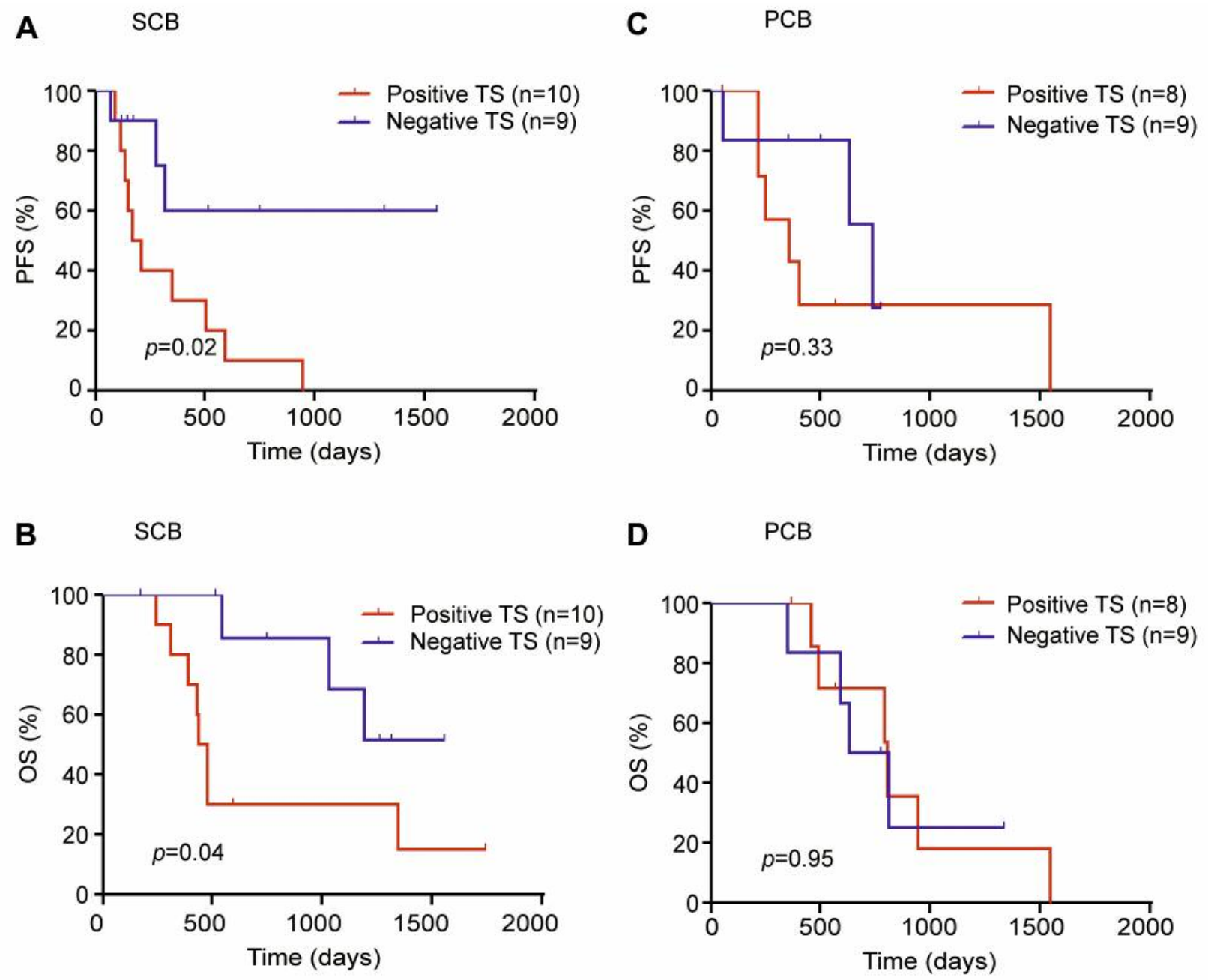

Figure 3. Kaplan-Meier survival curves according to the expression level of TS in SCB and PCB. The patients with positive TS expression following $S C B$ treatment yielded a significant worse PFS (A) and OS (B) compared to those negative for TS. No statistically significant difference in the PFS and $O S$ was observed between the patients with positive and negative TS expression ( $C$ and $D$, respectively).

There are several limitations in this study. First, our study has a small sample size, which may bias our results. However, since this is an exploratory randomized study, these results would need confirmation by a large-scale prospective study. Second, the expression of PD-L1 was not assessed in all registered patients. Any future chemotherapeutic strategy should consider combining SCB with ICIs, as a recent phase III study demonstrated that platinum-based chemotherapy that combined pemetrexed with ICIs significantly improved patients' survival compared to survival without ICIs (19). Since the targeting molecule for S-1 is similar to that of pemetrexed (TS), the combination of S-1 and ICIs is also expected to improve survival. However, little is known about the relationship between TS and PD-L1 expression in tumor cells and the clinical significance of the synergistic effect of S-1 with the anti-PD-1 antibody in human neoplasms.
Angiogenic agents are known to stimulate the immune system, while, conversely, immunotherapy is suggested to be anti-angiogenic, with VEGF playing a crucial role in the mediation of the immunosuppressive microenvironment (20). Therefore, combination chemotherapy that includes bevacizumab, such as SCB, may produce a synergistic effect with ICIs. Finally, $68.7 \%$ of 48 patients were evaluated using our planned predictive markers. Because of limited tissue samples, it remains unclear whether TS is a better predictor for SCB compared to PCB, and so it is necessary to confirm our results using a larger sample size.

In conclusion, the regimen of SCB achieved similar activity and tolerability to that of $\mathrm{PCB}$ based on the results presented here. TS expression was more predictive of the chemotherapeutic response in SCB compared to PCB, but not for PFS. Further prospective studies are warranted to 


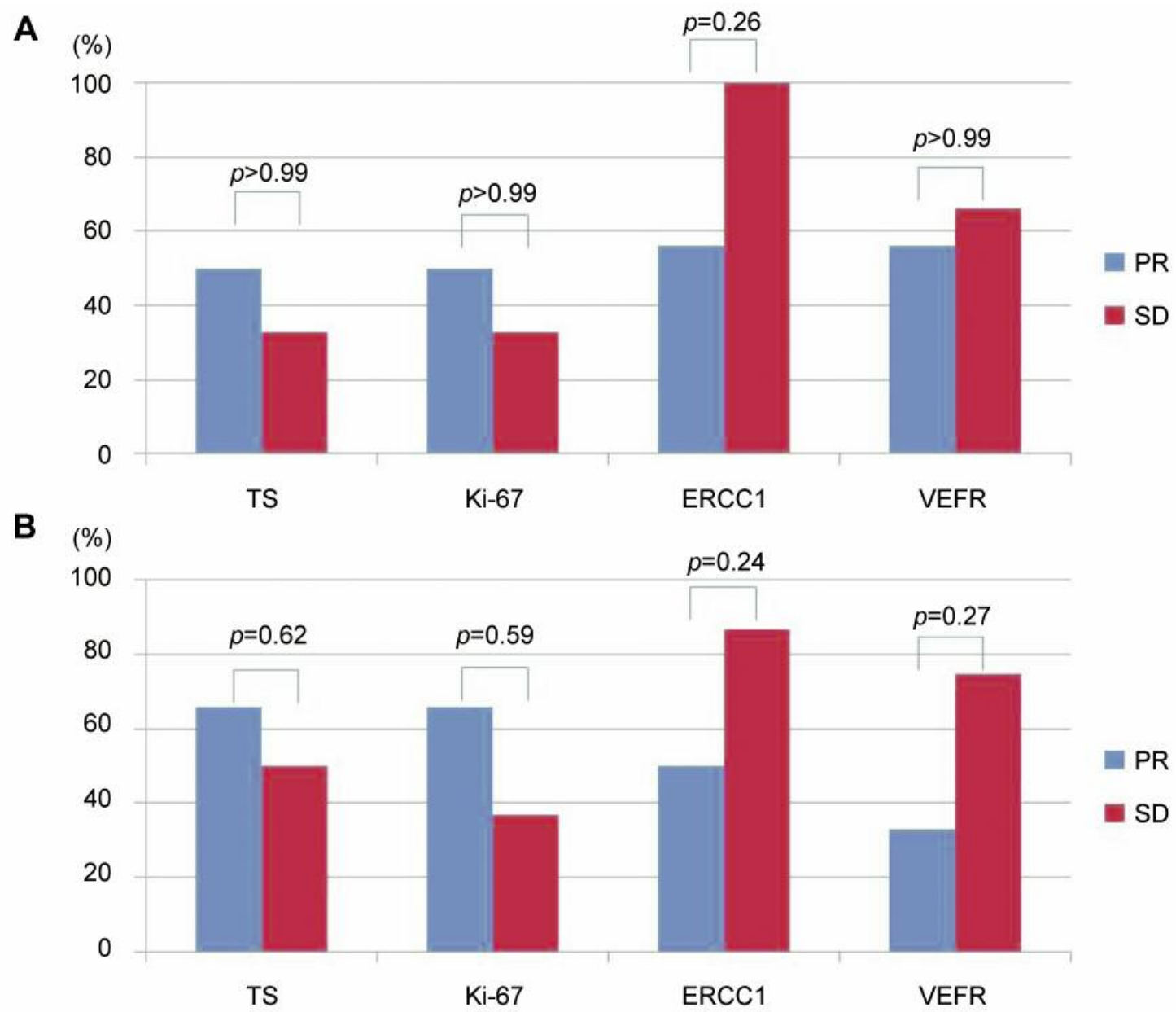

Figure 4. No statistically significant differences in the expression levels of biomarkers such as TS, ERCC1, Ki-67 and VEGF were observed between responder $(P R)$ and non-responder $(S D)$ in $A C B(A)$ and $P C B(B)$.

investigate the combination of SCB with ICIs in patients with advanced non-squamous NSCLC.

\section{Conflicts of Interest}

KK has received research grants and a speaker honorarium from Eli Lilly Company. All remaining authors have declared no conflicts of interest.

\section{Authors' Contributions}

KK and HI: Conception and preparation of the manuscript. RS, YM, NS, NK, YT, YA and SK: Management of the patient. MK, KM and IN: Statistical analysis and patient's data collection. YF, TH and TI: Revising the manuscript. All authors contributed and agreed with the content of the manuscript.

\section{Acknowledgements}

This research received no specific grant from any funding agency in the public, commercial or not-for-profit sectors.

\section{References}

1 Maemondo M, Inoue A, Kobayashi K, Sugawara S, Oizumi S, Isobe H, Gemma A, Harada M, Yoshizawa H, Kinoshita I, Fujita Y, Okinaga S, Hirano H, Yoshimori K, Harada T, Ogura T, Ando M, Miyazawa H, Tanaka T, Saijo Y, Hagiwara K, Morita S and Nukiwa T (North-East Japan Study Group): Gefitinib or chemotherapy for non-small-cell lung cancer with mutated EGFR. N Engl J Med 362: 2380-2388, 2010. PMID: 20573926. DOI: 10.1056/NEJMoa0909530

2 Sandler A, Gray R, Perry MC, Brahmer J, Schiller JH, Dowlati A, Lilenbaum R and Johnson DH: Paclitaxelcarboplatin alone or with bevacizumab for non-small-cell lung cancer. N Engl J Med 355: 2542-2550, 2006. PMID: 17167137.

3 Reck M, von Pawel J, Zatloukal P, Ramlau R, Gorbounova V, Hirsh V, Leighl N, Mezger J, Archer V, Moore N and Manegold C: Phase III trial of cisplatin plus gemcitabine with either placebo or bevacizumab as first-line therapy for nonsquamous non-small-cell lung cancer: AVAil. J Clin Oncol 27: 1227-1234, 2009. PMID: 19188680. DOI: 10.1200/JCO.2007.14.5466 
4 Barlesi F, Scherpereel A, Rittmeyer A, Pazzola A, Ferrer Tur N, Kim JH, Ahn MJ, Aerts JG, Gorbunova V, Vikström A, Wong EK, Perez-Moreno P, Mitchell L and Groen HJ: Randomized phase III trial of maintenance bevacizumab with or without pemetrexed after first-line induction with bevacizumab, cisplatin, and pemetrexed in advanced nonsquamous non-small-cell lung cancer: AVAPERL (MO22089). J Clin Oncol 31: 3004-3011, 2013. PMID: 23835708. DOI: 10.1200/JCO.2012.42.3749

5 Kaira K, Tomizawa Y, Yoshino R, Miura Y, Yoshii A, Iwasaki Y, Koga Y, Ono A, Hisada T, Minato K, Sato K, Kazama T, Ishihara S, Kohyama K, Fueki N, Saito R and Sunaga N: Phase II study of oral S-1 plus cisplatin with bevacizumab for advanced non-squamous non-small cell lung cancer. Lung Cancer 82: 103-108, 2013. PMID: 23927884. DOI: 10.1016/ j.lungcan.2013.07.008

6 Urata Y, Okamoto I, Takeda M, Hattori Y, Okuno K, Shimada T, Kurata T, Kaneda H, Miyazaki M, Terashima M, Tanaka K, Morita S, Nakagawa K, Negoro S and Satouchi M: Phase 2 study of S-1 and carboplatin plus bevacizumab followed by maintenance $S-1$ and bevacizumab for chemotherapy-naïve patients with advanced nonsquamous non-small cell lung cancer. Cancer 15: 2275-2281, 2013. PMID: 23558513. DOI: $10.1002 /$ cncr.28048

7 Okamoto I, Yoshioka H, Morita S, Ando M, Takeda K, Seto T, Yamamoto N, Saka H, Asami K, Hirashima T, Kudoh S, Satouchi M, Ikeda N, Iwamoto Y, Sawa T, Miyazaki M, Tamura K, Kurata T, Fukuoka M and Nakagawa K: Phase III trial comparing oral S-1 plus carboplatin with paclitaxel plus carboplatin in chemotherapy-naïve patients with advanced nonsmall-cell lung cancer: results of a West Japan Oncology Group Study. J Clin Oncol 28: 5240-5246, 2010. PMID: 21079147. DOI: $10.1200 / \mathrm{JCO} .2010 .31 .0326$

8 Kubota K, Sakai H, Katakami N, Nishio M, Inoue A, Okamoto H, Isobe H, Kunitoh H, Takiguchi Y, Kobayashi K, Nakamura Y, Ohmatsu H, Sugawara S, Minato K, Fukuda M, Yokoyama A, Takeuchi M, Michimae H, Gemma A and Kudoh S; Tokyo Cooperative Oncology Group: A randomized phase III trial of oral S-1 plus cisplatin versus docetaxel plus cisplatin in Japanese patients with advanced non-small-cell lung cancer: TCOG0701 CATS trial. Ann Oncol 26: 1401-1408, 2015. PMID: 25908605. DOI: $10.1093 /$ annonc/mdv 190

9 Shirasaka T, Yamamitsu S, Tsuji A and Taguchi T: Conceptual changes in cancer chemotherapy: from an oral fluoropyrimidine prodrug, UFT, to a novel oral fluoropyrimidine prodrug, S-1, and low-dose FP therapy in Japan. Invest New Drugs 18: 315-329, 2000. PMID: 11081568.

10 Takeda M, Okamoto I, Hirabayashi N, Kitano M, Nakagawa K: Thymidylate synthase and dihydropyrimidine dehydrogenase expression levels are associated with response to S-1 plus carboplatin in advanced non-small cell lung cancer. Lung Cancer 73: 103-109, 2011. PMID: 21111509. DOI: 10.1016/j.lungcan. 2010.10.022

11 Wang L, Wang R, Pan Y, Sun Y, Zhang J and Chen H: The pemetrexed-containing treatments in the non-small cell lung cancer is -/low thymidylate synthase expression better than +/high thymidylate synthase expression: a meta-analysis. BMC Cancer 14: 205, 2014. PMID: 24641970. DOI: 10.1186/1471-2407-14-205

12 Eisenhauer EA, Therasse P, Bogaerts J, Schwartz LH, Sargent D, Ford R, Dancey J, Arbuck S, Gwyther S, Mooney M, Rubinstein L, Shankar L, Dodd L, Kaplan R, Lacombe D and Verweij J: New response evaluation criteria in solid tumour:
Revised RECIST guideline (version 1.1). Eur J Cancer 45: 228247, 2009. PMID: 19097774. DOI: 10.1016/j.ejca.2008.10.026

13 Cancer Therapy Evaluation Program (CTEP): Common Terminology Criteria for Adverse Events (CTCAE) v 4.0. Available at: http://ctep.cancer.gov/protocolDevelopment/ electronic_applications/ctc.htm\#ctc_40

14 Kaira K, Serizawa M, Koh Y, Miura S, Kaira R, Abe M, Nakagawa K, Ohde Y, Okumura T, Naito T, Murakami H, Takahashi T, Kondo H, Nakajima T, Endo M and Yamamoto N: Expression of excision repair cross-complementation group 1, breast cancer susceptibility 1 , and $\beta$ III-tubulin in thymic epithelial tumors. J Thorac Oncol 6: 606-613, 2011. PMID: 21289518. DOI: $10.1097 /$ JTO.0b013e31820b9b35

15 Kaira K, Serizawa M, Koh Y, Miura S, Kaira R, Abe M, Nakagawa K, Ohde Y, Okumura T, Murakami H, Tsuya A, Nakamura Y, Naito T, Takahashi T, Kondo H, Nakajima T, Endo $\mathrm{M}$ and Yamamoto N: Expression of thymidylate synthase, orotate phosphoribosyltransferase and dihydropyrimidine dehydrogenase in thymic epithelial tumors. Lung Cancer 74: 419-425, 2011. PMID: 21550686. DOI: 10.1016/j.lungcan. 2011.04.001

16 Kaira K, Endo M, Abe M, Nakagawa K, Ohde Y, Okumura T, Takahashi T, Murakami H, Tsuya A, Nakamura Y, Naito T, Hayashi I, Kondo H, Nakajima T and Yamamoto N: Biologic correlates of ${ }^{18} \mathrm{~F}-\mathrm{FDG}$ uptake on PET in pulmonary pleomorphic carcinoma. Lung Cancer 71: 144-150, 2011. PMID: 20646779. DOI: 10.1016/j.lungcan.2010.05.021

17 Yamada K, Ichiki M, Takahashi K, Hisamatsu Y, Takeoka H, Azuma K, Shukuya T, Nishikawa K, Tokito T, Ishii $H$ and Hoshino T: A multicenter phase II trial of S-1 combined with bevacizumab after platinum-based chemotherapy in patients with advanced non-squamous non-small cell lung cancer. Cancer Chemother Pharmacol 78: 501-507, 2016. PMID: 27402398. DOI: $10.1007 / \mathrm{s} 00280-016-3101-\mathrm{Z}$

18 Niho S, Ohe Y, Ohmatsu H, Umemura S, Matsumoto S, Yoh K and Goto K: Switch maintenance chemotherapy using S-1 with or without bevacizumab in patients with advanced non-small cell lung cancer: a phase II study. Lung Cancer 108: 66-71, 2017. PMID: 286256650. DOI: 10.1016/j.lungcan.2017.02.018

19 Gandhi L, Rodríguez-Abreu D, Gadgeel S, Esteban E, Felip E, De Angelis F, Domine M, Clingan P, Hochmair MJ, Powell SF, Cheng SY, Bischoff HG, Peled N, Grossi F, Jennens RR, Reck M, Hui R, Garon EB, Boyer M, Rubio-Viqueira B, Novello S, Kurata T, Gray JE, Vida J, Wei Z, Yang J, Raftopoulos H, Pietanza MC and Garassino MC: KEYNOTE-189 Investigators. Pembrolizumab plus chemotherapy in metastatic non-small-cell lung cancer. N Engl J Med 378: 2078-2092, 2018. PMID: 29658856. DOI: $10.1056 /$ NEJMoa1801005

20 Manegold C, Dingemans AC, Gray JE, Nakagawa K, Nicolson M, Peters S, Reck M, Wu YL, Brustugun OT, Crinò L, Felip E, Fennell D, Garrido P, Huber RM, Marabelle A, Moniuszko M, Mornex F, Novello S, Papotti M, Pérol M, Smit EF, Syrigos K, van Meerbeeck JP, van Zandwijk N, Chih-Hsin Yang J, Zhou C and Vokes E: The potential of combined immunotherapy and antiangiogenesis for the synergistic treatment of advanced NSCLC. J Thorac Oncol 12: 194207, 2016. PMID: 27729297. DOI: 10.1016/j.jtho.2016.10.003

Received April 11, 2019

Revised April 28, 2019

Accepted April 30, 2019 